\title{
DOCUMENTOS
}

\section{[ La fundamentalidad del conocimiento y la reforma educacional en curso discurso de apertura, escuela de temporada universidad de chile, enero de 1998]}

\author{
Por María Loreto Nervi Haltenhoff \\ Directora Programa de Investigaciones en Estudios Pedagógicos, \\ Universidad de Chile
}

La Reforma Educacional que se está llevando a efecto en nuestro país se define como tal sólo a partir del discurso presidencial del 01 de mayo de 1996 aunque su gestación se remonta a 1990, año de la asunción del primer gobierno democrático, al término del largo período autoritario. Por lo tanto, hoy se está iniciando prácticamente el octavo año de un intenso y decidido trabajo dedicado a lo que se ha dado en denominar globalmente "la modernización del sistema educacional", cuyas razones originarias, fundantes y políticamente consensuales, se ubican en el documento "Los Desafíos de la Educación Chilena frente al Siglo XXI" elaborado por el Comité Técnico Asesor del Diálogo Nacional sobre la Modernización de la Educación, profusamente divulgado en el contexto nacional y en países latinoamericanos que se inspiran en sus directrices, con el propósito también de nutrir la propia reflexión e implementar las transformaciones que el término de milenio exige, prácticamente, a todos los sistemas escolares.

Para nuestro beneficio, además, contamos con una descripción precisa del desarrollo de la reforma que se ha llevado a efecto en nuestro país y que ubicamos en un sintético pero muy ilustrativo y honesto documento de sólo 34 páginas escrito por Cristián Cox, Coordinador Nacional del Programa de Mejoramiento de la Calidad y Equidad de la Educación, programa del que se derivará posteriormente el concepto integral de reforma que hoy todos utilizamos.

En tal escrito denominado "La Reforma Educacional Chilena: Contexto, Contenidos, I mplementación", de mayo de 1997, el autor da cuenta de las razones que han inspirado el proceso, de las políticas aplicadas a los diversos niveles del sistema en todas sus dimensiones, de sus modos estratégicos de desarrollo, de los implementos financieros y materiales, de los logros en algunas líneas de acción, de las distonías o asincronías detectadas entre distintos ámbitos de políticas de intervención e incluso de las actuales limitaciones que lo afectan.

Teniendo en consideración los dos documentos señalados, el primero de carácter fundante y el segundo de carácter descriptivo evaluativo, -sin el ánimo de simplificar el análisis pero por razones más que atendibles obviaré los aspectos institucionales, políticos y financieros y me referiré sólo a lo que a mi juicio constituye el elemento central - que se ubica de modo no suficientemente explícito en los textos - y que justifica, obliga y dinamiza el actual proceso de reforma, y como nunca antes, lo hace extensivo desde el nivel de gobierno a toda la arquitectura cultural del país.

Se trata de lo que aquí denomino: fundamentalidad del conocimiento, haciendo referencia a la importancia y a la magnitud del impacto de la capacidad que ha desplegado la humanidad - especialmente después del término de la Segunda Guerra Mundial -, para generar, producir y desarrollar ideas, para renovar organizaciones y articulaciones teórico/conceptuales, para producir modernas tecnologías de apoyo y 
fundamentalmente, para generar conciencia acerca de la provisionalidad del conocimiento la que, necesariamente cambia nuestro modo de aproximarnos a la realidad.

A objeto de proseguir con el argumento quisiera recurrir a los planteamientos de Vattimo en su obra "La Sociedad Transparente", donde se proponen algunas hipótesis de trabajo que ayudan a desarrollar de mejor modo la comprensión que requiere el cambio de clima cultural externo a la escuela y las repercusiones que está teniendo ello en el mundo educativo.

Lo que Vattimo nos plantea, y ya lo vamos a exponer, nos pone - en esta etapa histórica del sistema escolar - ante la evidencia irreductible de encontrarnos frente a las cenizas de la escuela de enseñar a leer y escribir, así como también frente a la ceremonia fúnebre de la escuela transmisiva de un saber absoluto para su conservación y para la reproducción del poder de élite. Hoy estamos frente a una escuela masificada, que desde la década de los 80 viene concretizando la aspiración de la lógica cuantitativa; pero también, este nuevo momento histórico nos ha puesto frente a un sistema escolar cuyos datos de realidad refieren que sus procesos y resultados no toleran el examen de la lógica cualitativa.

El antiguo orden elitario de distribución del conocimiento está en jaque así como lo está su transmisión enciclopédica.

De más está referirse, en el estricto caso de nuestro país, a los antecedentes que la investigación ministerial produjera y diera a conocer entre 1992 y 1994; si lo hiciese, más de alguno de nosotros se vería seriamente afligido por una sensación de catástrofe y de colapso social.

Lo que es necesario considerar ahora, además de la masificación del sistema, que exigió a su vez la masificación en la formación de profesores, es la irrelevancia e ineficiencia de un sistema transmisivo de conocimientos estancos, muchas veces desactualizados y disociados de los saberes que circulan con liviana fluidez en el mundo extra-escolar.

Vattimo plantea en la obra mencionada, para estos tiempos de fin de siglo, la necesidad de examinar:

el rol que juegan los medios de comunicación masivos en el proceso de distribución y de consecuente democratización del saber, la crisis producida por la actual pluralidad de discursos, la imposibilidad de dar un criterio último y estable al conocimiento y la búsqueda de nuevas dimensiones para el concepto de "verdad", ya no como conformidad con un estado de cosas sino como correspondencia de diálogo entre textos...

Todas éstas son hipótesis de trabajo que no resultan fáciles ni cómodas para el sistema educativo, en todos sus niveles. Hoy no es más posible para ningún sistema escolar, frente a la explosión del conocimiento y a su circulación, seleccionar para la escuela conocimientos "fuertes", absolutos y resolutivos porque el mundo cognitivo externo a la escuela se caracteriza por la pluralidad, la diferencia, la multiplicidad, el entrecruzamiento de saberes y el contraste de posiciones. 
Dado este estado de cosas, de carácter planetario por lo demás, nuestro sistema educativo debe asumir la provisionalidad del conocimiento -que no es relativismo-, la multiplicidad de articulaciones conceptuales y teóricas que puede soportar y las plurales lecturas disciplinarias a las que puede ser sometido cualquier problema cultural.

Más allá de los estrictos ámbitos de gestión de política gubernamental de reforma que por ahora ha intervenido sólo en el sistema escolar - toda la estructura cultural de la sociedad está llamada a comprender y a asumir los costos y beneficios de un cambio cultural que más parece un ambicioso salto cultural. Salto que nos puede sorprender en el vacío si no alentamos la elevación de nuestro desarrollo integral pues, no será fácil para el sistema educativo - tanto en el nivel secundario como el superior -; no nos será sencillo romper con la concepción histórica tradicional del conocimiento acabado, susceptible de ser transmitido con orden y sistematicidad bajo la lógica histórico cronológica enciclopédica.

Estamos frente a una especie de "desorden cultural" caracterizado por la provisionalidad de las verdades que se creían tales y por la ausencia de centralismo difusor de discursos emancipatorios de la educación. Se va superando la concepción de la producción y difusión institucional central única y monolítica y la lógica lineal de transmisión del saber.

Lo acaecido a nivel mundial con la conformación del supra poder del conocimiento, con las enormes inversiones que las sociedades hacen en el campo de las comunicaciones y del flujo de la información, con el casi inmediato acceso de miles de personas a cualquier dato a través del supermarket de las redes, nos coloca en una nueva condición existencial y, dependerá del nivel y grado de conciencia y de participación de los actores en ese escenario si nos enfrentamos a él con la opacidad y el oscurantismo de la dependencia acrítica o asumimos la enorme exigencia que supone la independencia luminosa de sujetos activos frente a una sociedad donde el conocimiento circula por canales abiertos y que Vattimo adjetiva como "transparente". La tarea escolar de estos tiempos entonces, y así lo ha asumido nuestra reforma, no puede seguir siendo la de bloquear - si así fuese, en el corto plazo tal vez estaríamos asistiendo, como dice Lyotard, al funeral de la era del Profesor - sino, incrementar la relación de los jóvenes con la dinámica del saber social y con la pluralidad de manifestaciones que éste asume en el mundo contemporáneo. De allí que los principios fundantes y las directrices de las transformaciones que la reforma está llevando a cabo tengan su origen en un necesario realismo que en el corto plazo deberá materializarse a través de una mayor y mejor articulación en las prácticas de aula entre los "saberes de la escuela" y los actuales "saberes no escolares".

El desafío es muy interesante, sobrepasa al sistema escolar, compromete a mi juicio a la Universidad como principal institución de la arquitectura cultural de la sociedad y a ella compete el generar un espacio para el examen permanente del estatuto de la cultura contemporánea. Un centro de estudios culturales de actividad sistemática podría colaborar en esta tarea para la que se requiere romper con la rutinización de los modos tradicionales de pensar en parcelas de conocimiento de carácter absoluto, promover lecturas multidisciplinarias y abrirse a nuevas posibilidades de vínculos intra - estructurales e inter institucionales.

El actual estado subsidiario requiere que las instituciones civiles participen de los espacios que éste va paulatinamente liberando a través del proceso decentralizador y, especialmente en el campo cultural y educativo urge la presencia activa de 
instituciones que desde legítimas posiciones colaborativas y críticas, entusiastas o ponderadas acompañen los procesos de cambio con propuestas meditadas, particularmente en estos tiempos en que al parecer, si no estamos ante reformas educacionales permanentes, sí estamos frente a necesarias flexibilizaciones y permeabilizaciones del currículo a objeto que el saber actualizado fluya sin tropiezos por las salas del sistema educativo y pueda ser sometido a juicio intelectual y ético por parte de maestros y estudiantes.

A partir de allí será posible dar un nuevo impulso a lo que la Universidad de Chile viene haciendo en el campo de la formación de profesores desde 1994, en un esfuerzo muy sustantivo de fortalecimiento de la formación pedagógica y de dignificación de su función profesional, sustrayéndola de concepciones voluntaristas, apostólicas o espontaneístas, curiosamente aún vigentes. El propósito, y a objeto de colaborar efectivamente con los procesos de reforma y de participar con solvencia en las transformaciones sociales y culturales del país, es el de situar a la profesión docente en un contexto de márgenes disciplinarios y profesionales definidos por una formación científica para un desempeño intelectual de animación y de problematización cultural. Asumimos entonces la fundamentalidad del conocimiento para apoyar con voluntad consciente y crítica cualquier proceso de transformación social más aún si se trata de la formación de las generaciones jóvenes y de su derecho a ser sujetos en democracia e interlocutores competentes.

Estoy cierta que la Universidad se movilizará en esas direcciones, integrará a la formación de sus docentes la disquisición cultural y curricular y esta reforma - la más significativa de los últimos 30 años si se consideran sólo las transformaciones curriculares que impulsa - podrá contar con actores que materializarán el debate inteligente que este proyecto nacional espera sea vida escolar cotidiana.

Muchas gracias y auguro para estas jornadas la mayor y mejor proliferación de ideas. 